\title{
Effect of Packaging Materials and Time Period for Damage in Packaging and Weight Loss in Packed Wheat Flour (Triticum aestivum L.) by Red Flour Beetles Tribolium castaneum Herbst (Coleoptera: Tenebrionidae)
}

\author{
Muhammad Asfand Yar $^{1}$, Muhammad Waqar Hassan ${ }^{1}$, Mansoor Ahmad ${ }^{1}$, Farhan Ali $^{1}$ \& Moazzam Jamil ${ }^{1}$ \\ ${ }^{1}$ University College of Agriculture and Environmental Sciences, The Islamia University of Bahawalpur, \\ Bahawalpur, Pakistan \\ Correspondence: Muhammad Waqar hassan, University College of Agriculture and Environmental Sciences, The \\ Islamia University of Bahawalpur, Bahawalpur 63100, Pakistan. Tel: 92-629-255-471. E-mail: \\ waqar.hassan@iub.edu.pk; waqar_722@hotmail.com
}

Received: January 18, 2017

Accepted: February 23, $2017 \quad$ Online Published: March 15, 2017

doi:10.5539/jas.v9n4p242

URL: https://doi.org/10.5539/jas.v9n4p242

The research is financed by Higher Education Commission (HEC) of Pakistan.

\begin{abstract}
This study evaluates three popular loose plastic packaging namely polyethylene (PE), polypropylene (PP) and polyvinylchloride (PVC) for damage in packaging and weight loss in packed wheat flour by Tribolium castaneum Herbst (Coleoptera: Tenebriondiae) for three different time periods. The study lasted for three months and data was recorded three times with 30 day interval between data recordings to see damages in packaging, i.e., holes and penetrations made by beetles in packaging; number of beetles inside packages were counted to see their population growth after a given time period inside packed wheat flour and weight loss in wheat flour. Maximum holes by beetles were in polyethylene packaging, penetrations and numbers of beetles were more in polyethylene packaging type. Similarly weight loss in wheat flour was also more in polyethylene bags in contrast with other packaging materials used $(\mathrm{P}<0.05)$. Effect of time period showed significantly more weight loss in wheat flour after 90 days than after 60 or 30 days $(\mathrm{P}<0.05)$ however time period had non-significant effect on holes made by beetles into packaging and penetrations as well as numbers of beetles counted or their population growth after given time period in different packaging materials $(P>0.05)$. These results revealed that out of three packaging materials tested polyethylene was a susceptible packaging material because it had maximum number of holes and penetrations by insects into them. Similarly maximum weight loss occurred in polyethylene. Effect of time period showed non-significant effect on holes and insect penetrations into packaging materials. However more weight loss occurred after more time period than after less time period. These results are important and can be employed for integrated management of T. castaneum regarding packed foodstuffs i.e., wheat flour.
\end{abstract}

Keywords: red flour beetle, Tribolium castaneum, wheat, Triticum aestivum, weight loss, resistant packaging, polymer

\section{Introduction}

Food products are normally packed in plastic bags. The success of packing technique is that the packed foodstuff is free from insects until these are consumed (Mullen \& Mowery, 2000). In case of any packaging in stored form include an insect's life stage it could pollute other packages which can cause decline in the quantity and quality of the produce. Postharvest losses and waste of stuff are most important trouble in the food manufacturing of world. It has been found that if a sole insect goes into in a packaging it sets the foundation for deterioration in the amount as well as it harms the quality. In addition it can confer conditions fit for microorganism like fungi to knock the food. Countless diseases e.g., cancer types are due to the use of infected foods (Jakic-Dimic et al., 2009). Food wastage is about 1.3 billion tons per annum in production, supply and in homes (Quested et al., 
2011). News from diverse countries for example USA, Britain and Sweden has revealed that about one third from procured food is wasted at food provision institutions and homes (Wikström \& Williams, 2010).

There are two types of insects that attack packaged products, "penetrators", which are insects that can bore holes through materials and "invaders", which are insects that enter packaging through existing holes (Highland, 1984; Newton, 1988). Stored wheat is attacked by several insects. Tribolium castaneum is found all over the world and is the most serious stored product pest of damaged wheat and its by-products. The post-harvest losses by $T$. castaneum are estimated to be $15-20 \%$ which is great loss of millions of rupees in a developing country like Pakistan (Khattak \& Shafique, 1986). Adult beetle and larvae feed on stored food stuff (Atwal, 1976; Dars et al., 2001). It is an important pest species of stored agricultural grain products in most warm region of world and most abundant insect in retail stored (Padin et al., 2002).

Today's consumers are faced with a number of challenges from the moment they enter the grocery store. The thousands of packages are designed not only to attract and sell the products but to maintain the highest quality. Food and beverage packaging make up more than $\$ 70$ billion of the United States packaging market and more than $\$ 200$ billion worldwide (Wilkinson, 1998). Plastic based packaging using the films like polypropylene, polyethylene, polyvinylchloride and cellophane are mostly used for packaging purposes (Odian, 2004). Paper and board packaging is the most common material and generally considered the most susceptible to insect attack. The widespread use of these susceptible packaging materials for food products is important because losses from insect infestation of packaged foods are the sum cost of growing, harvesting, transportation, processing, and packaging (Allahvaisi et al., 2010). The packaging of products is the last line defence for the processors against insect infestation of their finished products (Hou et al., 2004). When developing a package for a food product, several factors must be considered. The type of package (rigid or flexible), ability of the package to maintain food quality, cost, and availability of materials, and consumer acceptance are essential. An often overlooked problem is the ability of the package to be resealed. Insects have the ability to enter in sealed plastic packages and these can destroy different products from edibles to any other precious materials which attract them.

Previous research include finding of insect resistant packaging against different storage insect pests and search of better packaging for fumigation efficacy over short time scale up to two weeks at the most. We have so far studied behaviour of three types of loose plastic packaging in terms their susceptibility to penetration or invasion by $T$. castaneum or other storage pests and fumigation efficacy by phosphine as affected by different packaging has been elucidated (Qasim et al., 2013; Hassan et al., 2014; Hassan et al., 2016). This research is for the first time about investigation of resistant packaging against $T$. castaneum for a period of three months. It includes the insect ability to make holes in three standard foodstuff packaging and determination of susceptible packaging material against this pest. Insect ability to create holes in packaging, their entry through holes and growth in their population occurring over three month period is calculated and finally a decrease in weight from initial weight of packed wheat flour is studied. Following were main objectives of this study:

1) Effect of packaging materials on holes, penetration as well as population growth in packaging and weight loss in wheat flour by T. castaneum.

2) Effect of time period on on holes, penetration as well as population growth in packaging and weight loss in wheat flour by $T$. castaneum.

\section{Materials and Methods}

\subsection{Collection and Rearing of T. castaneum}

Population of red flour beetle was collected from godowns and grain markets of Bahawalpur region. Insect collection was deposited under designated collection lots. For identification purpose samples of adults were preserved in ethanol 75\% and identified as T. castaneum through comparison with our previous red flour beetle adult populations and also with the available literature. Adults are 3-4 $\mathrm{mm}$ long, reddish brown colour beetles with curved elytra (forewings) along margins and have a flattened body. Antenna from 3 segmented club towards the tip. However the closely related species $T$. confusum antenna forms a gradual and four segmented club and can be distinguished from T. castaneum on this basis. Eggs are about $0.5 \mathrm{~mm}$ long, white or colourless and cylindrical. They are sticky and remain in flour and fasten to containers. The larvae are yellowish-white, slender and body has fine hairs. T. castaneum was reared in the laboratory of Entomology, University College of Agriculture and Environmental Sciences, The Islamia University of Bahawalpur. Red flour beetles were reared in plastic jars containing whole wheat flour and yeast as diet (95:5 by weight) in rearing room under optimum conditions of temperature and relative humidity $28 \pm 2{ }^{\circ} \mathrm{C}$ and $65 \pm 5 \% \mathrm{R}$. H. respectively. The rearing room is provided with an air conditioner and humidifier to maintain the temperature and relative humidity at stated optimum levels and measured with thermometer and hygrometers. Plastic jars (500 $\mathrm{ml}$ volume) were prepared 
with lids having wire gauze of smallest size to ensure air movement through the jar but to restrict of movement of insects in an outside these jars. Uniform age adults were obtained by letting 50 pairs (male and females) of $T$. castaneum to lay eggs on a diet consisting of whole wheat flour in different plastic jars (500 ml volume) for a period of one week inside the rearing room. After that adults were removed and commodity with eggs was left for egg development for a period of one month. After one month from the date of sifting parent adults when sufficient adults had emerged as new generation these were F1 of parents sifted out and subsequently were used in experiments.

\subsection{Packaging Material and Experimental Setup}

For packing the host commodity, three types of packaging material were used namely polyethylene, polypropylene and polyvinylchloride. Three types of plastic films $(0.02 \mathrm{~mm}$ thickness $)$ were purchased from whole sale plastic market in Lahore, Pakistan at $350 \mathrm{PKRs} / \mathrm{Kg}$. Thickness of films was ascertained with digital micrometer (Mitutoyo Corpoation Japan). Subsequently consumer size plastic bags of $8 \times 10 \mathrm{~cm}^{2}$ size were prepared using a pair of scissors and an impulse sealer by heat sealing process. After preparation of plastic bags required for experiments need, 20 grams of whole wheat flour was weighed on digital electronic balance and packed in all three types of packaging materials. After filling with wheat flour packets were sealed again by heat sealing process using same impulse sealer to represent consumer size packed foodstuffs in small pouches.

Three types of plastic packets containing wheat flour as substrate were placed in plastic jars (500 ml volume) vertically along walls of jars. Each jar had a set of three packets (polyethylene, polypropylene and polyvinylchloride). 100 homogeneous age insects were released in the middle of every jar making one replication and lid of the jar was closed. Same procedure was repeated for all four jars making four replicates in total.

\subsection{Data Collection}

Data was collected for three times with a 30 day time interval between every data recording. On each occasion of data collection, each pack was examined from the outside for any damages like holes. After that packages were opened to note penetrations made by insects and number of insects inside these packets (adults and larvae both) were counted showing an increase in population of insects. It might be important to note that $T$. castenum feeds primarily on powder like food materials like wheat flour and these cannot feed on sound cereal grains while their eggs are present inside such food materials. Therefore presence of larvae alongside adults inside packets was an indication of their population growth which was counted and we only resealed adults as experiment organisms. At the end weight loss was determined by using the following Equation (1):

$$
\text { Weight } \operatorname{loss} \%=(\text { Initial weight }- \text { Final weight }) /(\text { Initial weight }) \times 100
$$

After data collection and measurement of weight loss, packets along with wheat flour were sealed again and to note treatment effects for upcoming data recording dates. Data was analyzed statistically by using SPSS software (Version 2007) and by non-parametric Kruskal-Wallis H. Test at 5\% probability level; because according to homogeneity of variance test data was found non-normal $(\mathrm{p} \leq 0.001)$.

\section{Results}

\subsection{Effect of Packaging}

Maximum number of holes, maximum penetrations/population growth of insects and maximum weight loss occurred in polyethylene packaging followed by polypropylene and polyvinylchloride packaging. Holes, insect penetrations/population growth and weight loss were greater for polyethylene packaging followed by polypropylene and polyvinylchloride packaging (Table 1). Result showed that in relation to three types of packaging materials, the weight loss was non-significant as affected by packaging types but more weight loss occurred in polyethylene than in polypropylene and polyvinylchloride $(\mathrm{P}>0.05$; Table 1$)$. However penetrations or population growth of insects and holes were significant in relation to three type of packaging materials. Maximum penetrations/population growth was seen in polyethylene followed by polypropylene and polyvinylchloride with mean ranks of $26.50,14.50$ and 14.50 respectively $(\mathrm{P}<0.001$; Table 1). Similarly holes made by beetles were greater in polyethylene than in polypropylene or polyvinylchloride packaging with mean ranks of 30.50 for polyethylene compared with 12.50 for both polypropylene and polyvinylchloride packaging ( $\mathrm{P}$ $<0.001$; Table 1).

\subsection{Effect of Duration}

Weight loss in 90 days was significantly more than the weight loss after 60 and 30 days $(\mathrm{P}<0.001$; Table 1$)$ and the results for penetration and numbers of holes were non-significant $(P>0.05$; Table 1). However more 
penetration occurred after 60 days followed by 90 days. Similarly holes made by beetles were more after 60 or 90 days than after 30 days. Numbers of holes were similar after 60 or 90 days.

Test statistics showed significantly more weight loss after 90 days (26.92 mean rank) followed by 60 days (19.75 mean rank) and minimum weight loss occurred after 30 days ( 8.83 mean rank $)(\mathrm{P}<0.001$; Table 1). Penetrations and population growth was non-significant but it was more after 60 days (19.54 mean rank) compared with 30 or 90 day time intervals (mean ranks of 17.00 and 18.96 respectively). Holes in packaging were also recorded more after 60 or 90 day (18.75 mean ranks) time interval than after 30 days (18.00 mean rank) with non-significant difference between mean ranks (Table 1; $\mathrm{P}>0.05$ ).

\section{Discussion}

Damages in packaging in the form of holes, insect penetrations/population growth and weight loss in wheat flour were studied with respect to effect of packaging type and time intervals. The results showed that holes made by insects, insect penetrations and population growth of insects after penetrations and more weight loss occurred at the most in polyethylene type of packaging compared with polypropylene and polyvinylchloride packaging. Out of three packaging materials tested, polyethylene proved to be a rather susceptible packaging type against this pest. These results are in agreement with that of Mullen et al. (Mullen et al., 2012) that stated polyethylene to be a susceptible packaging material among different packing types. T. castaneum beetles could only manage to damage and create holes in polyethylene packets and subsequently it entered through holes in polyethylene packed wheat flour. This study is in agreement with our previous findings in which it was proved that out of three different packaging materials tested; polyethylene was a susceptible packaging material against red flour beetle in 2013, 2014 and 2016 (Qasim et al., 2013; Hassan et al., 2014; Hassan et al., 2016). This study is also in agreement with a study which reports that polymers like polyethylene and cellophane could be penetrated by certain stored grain insect pests (Cline, 1978; Allahvaisi, 2010). It has been checked (Wikström \& Williams, 2010) that polymers permeability for some stored grain insect pests. According to their results there was significant difference among polymers permeability for the studied stored product pests and it was concluded that polypropylene was least penetrated by insect pests. In our results polypropylene and polyvinylchloride films remained resistant to penetration by this pest.

It is important to note that it was the first time we studied damages and weight loss of packed foodstuff in a three months time period by red flour beetles. Results showed that insect penetrations and population growth was significantly more in polyethylene. Insect that managed to enter in polyethylene packaging; these kept on reproducing and showed increase in their population numbers. No penetrations and population growth in packaging was seen in other packaging materials where beetles could not enter packaging.

Weight loss from initial amount packed was determined when data was observed. Significantly more weight loss occurred in polyethylene than in other two packaging types. It is important to note that a little weight loss however occurred in other two packaging materials which were negligible or near to zero. Fractions of weight loss in other two packets which had no holes and penetrations by beetles might be due to handling of these packets and during data recording. These little weight loss in these packets could be through minor pores or imperfect seals in those packaging. However in future studies it is recommended that it would be much more beneficial to note minor weight loss through packets by some damages other than those made by insects.

The study of time interval revealed that more holes were recorded after 30 days than after 60 days or 90 days. Penetrations were more after 60 days followed by 90 days and least numbers of penetrations were after 30 days but there was non-significant difference in penetration by beetles with respect to three tested time periods. These results are in agreement with our previous findings (Qasim et al., 2013) which observed the effect of time period on penetrations in packaging materials. Previous results showed that more penetrations were seen after first 3 days time interval than were after 6 days time interval. It was observed that penetrations made by insects into packaging varied but remained non-significant due to effect of time period. Current results showed more holes observed after 30 days than they become constant. Insect penetration was also non-significant with respect to three tested time periods. However more penetrations and population was seen after 60 days followed by 90 days and least after 30 days time period. It is important to note that $T$. castaneum are primarily invaders rather than penetrators of packaging materials (Newton, 1988). Therefore upon first creation of holes maximum number beetles managed to enter through those holes and further holes were not created.

Our previous study (Hassan et al., 2014) also emphasized that $T$. castaneum were damaging against polyethylene packed wheat flour with respect to two different test arena i.e., tests carried in $500 \mathrm{ml}$ volume jars as well as tests conducted in 0.7 meter $^{3}$ tin containers. Those results confirmed that polyethylene was susceptible packaging material in both small and large volume test conditions (Hassan et al., 2014). Present results show that $T$. 
castaneum beetles proved similarly virulent against same packaging type i.e., polyethylene both in longer time spans of three months and shorter time span of 3 to 6 day time periods as revealed in our earlier results.

However more weight loss observed after 90 days followed by 60 and 30 days and there was also significant difference in weight loss by beetles with respect to three tested time periods. This is obvious that more time period led to multiplication of beetles inside packages and more population caused more weight loss in wheat flour.

Table 1. Effect of packaging types and time period on holes, penetrations (population growth) in packaging and weight loss in packed wheat flour by $T$. castaneum

\begin{tabular}{|c|c|c|c|c|c|c|c|c|}
\hline \multirow[b]{2}{*}{ Parameters } & \multicolumn{4}{|c|}{ Ranks } & \multicolumn{4}{|c|}{ Ranks } \\
\hline & $\begin{array}{l}\text { Packaging } \\
\text { effect }\end{array}$ & $\mathbf{N}$ & $\begin{array}{l}\text { Mean } \\
\text { Rank }\end{array}$ & Test statistics & $\begin{array}{l}\text { Duration } \\
\text { effect }\end{array}$ & $\mathbf{N}$ & $\begin{array}{l}\text { Mean } \\
\text { Rank }\end{array}$ & Test statistics \\
\hline \multirow[t]{4}{*}{ Weight loss } & $\mathrm{PT}$ & 12 & $24.42 \mathrm{~ns}$ & Chi-Square: 5.896 & 30 days & 12 & $8.83 \mathrm{c}$ & Chi-Square: 18.350 \\
\hline & PP & 12 & 16.17 & Df: 2 & 60 days & 12 & $19.75 b$ & Df: 2 \\
\hline & $\mathrm{PVC}$ & 12 & 14.92 & Asymp. Sig: .052 & 90 days & 12 & $26.92 \mathrm{a}$ & Asymp. Sig: .000 \\
\hline & Total & 36 & & & Total & 36 & & \\
\hline \multirow{4}{*}{$\begin{array}{l}\text { Penetration/population } \\
\text { growth }\end{array}$} & PT & 12 & $26.50 \mathrm{a}$ & Chi-Square: 19.592 & 30 days & 12 & $17.00 \mathrm{~ns}$ & Chi-Square: .723 \\
\hline & PP & 12 & $14.50 \mathrm{~b}$ & Df: 2 & 60 days & 12 & 19.54 & Df: 2 \\
\hline & $\mathrm{PVC}$ & 12 & $14.50 \mathrm{~b}$ & Asymp. Sig: .000 & 90 days & 12 & 18.96 & Asymp. Sig: .696 \\
\hline & Total & 36 & & & Total & 36 & & \\
\hline \multirow[t]{4}{*}{ Holes } & $\mathrm{PT}$ & 12 & $30.50 \mathrm{a}$ & Chi-Square: 33.507 & 30 days & 12 & $18.00 \mathrm{~ns}$ & Chi-Square: .058 \\
\hline & PP & 12 & $12.50 \mathrm{~b}$ & Df: 2 & 60 days & 12 & 18.75 & Df: 2 \\
\hline & $\mathrm{PVC}$ & 12 & $12.50 \mathrm{~b}$ & Asymp. Sig: .000 & 90 days & 12 & 18.75 & Asymp. Sig: .971 \\
\hline & Total & 36 & & & Total & 36 & & \\
\hline
\end{tabular}

Note. Kruscal Wallis H. Test used to generate mean ranks for effect of packaging and duration on three different outcomes. PT: Polyethylene, PP: Polypropylene, PVC: Polyvinylchloride, ns; non-significant, mean difference is significant at $5 \%$ probability level.

As soon as an insect creates an entrance hole inside a packaging it gives route for other population to follow this entry route and these multiply inside the packaging leading to more damage and weight loss in quantity as well as quality of foodstuffs is affected badly. Jianhua and Dan (2015) checked infestation by cigarette beetles into wheat flour either packed in different sorts of packaging or in unpacked open wheat flour. After 45 days of releasing eggs and adults of cigarette beetles into different packed or open wheat flour they found that both aluminum foil and plastic bags had the greatest resistance to package invasion by L. serricorne compared with either unpackaged wheat flour or packaging of different types other than plastic bags and aluminum foil.

This study emphasized the importance of packaging materials to pack foodstuffs. It has been stated that it may be more economical to make the outer shipping container insect resistant; it may be more desirable to make the consumer-sized package insect proof (Mullen, 1994).

\section{Conclusions}

These results conclude that polyethylene is a susceptible packaging material in terms of damages (holes) as well as penetrations or population growth by T. castaneum and it resulted in significantly more weight loss in wheat flour than in other packaging. More time period led to more weight loss in wheat flour but damages like holes and insect penetrations and population growth was more after medium time interval of two months compared with three months duration.

\section{References}

Allahvaisi, Pourmirza, A. A., \& Safaralizade, M. H. (2010). The study on polymers permeability for foodstuffs packaging by some serious species of stored pest insects and phosphine gas. Journal of Agriculture Technology, 6, 747-759.

Atwal, A. S. (1976). Insect pest of stored grain and other product. Agric. Pest India South-East Asia (pp. 389-415). Kalyani Publishers, New Delhi. 
Cline, L. D. (1978). Penetration of seven common packaging materials by larvae and adults of eleven species of stored product insects. Journal of Economic Entomology, 71, 726-729. https://doi.org/10.1093/jee/71.5.726

Dars, F., Rustamani, M. A., Khupo, R. D., \& Baloch, H. B. (2001). Effect of wheat grain moisture on infestation of red flour beetle. Pakistan Journal of Zoology, 33, 189-200.

Hassan, M. W., Gulraize, Rehman, F. U., Najeeb, H., Soahil, M., Irsa, B., ... Chaudhry, M. S. (2016). Evaluation of standard loose plastic for the management of Rhyzopertha dominica (F.) (Coleoptera: Bostrichidae) and Tribolium castaneum Herbst (Coleoptera: Tenebrionidae). Journal of Insect Science, 16, 1-9. https://doi.org/10.1093/jisesa/iew075

Hassan, M. W., Qasim, M. U., Iqbal, J., \& Jamil, M. (2014). Study of penetration ability by Tribolium castaneum (Herbst.) (Coleoptera: Tenebrionidae) through different loose plastic packaging. Journal of Pure and Applied Sciences, 24-33(1-2), 17-20.

Highland, H. A. (1984). Insect infestation of packages. In F. J. Bau (Ed.), Insect management for food processing (pp. 311-320). American association of cereal chemist, St. Paul, MN.

Hou, X., Fields, P., \& Taylor, W. (2004). The effect of repellents on penetration into packaging by stored-product insects. Journal of Stored Product Research, 40, 47-54. https://doi.org/10.1016/S0022-474X(02)00063-2

Jakic-Dimic, D. K., Nesic, K., \& Petrovic, M. (2009). Contamination of cereals with aflatoxins, metabolites of fungi Aspergillus flavus. Biotechnology in Animal Husbandry, 25, 1203-1208.

Jianhua, L. Ü., \& Dan, M. A. (2015). Effect of wheat flour packaging materials on infestation by Lasioderma serricorne (F.). Journal of Food Protection, 78, 1052-1055. https://doi.org/10.4315/0362-028X.JFP-14-438

Khattak, S. U., \& Shafique, M. (1986). Varietal susceptibility studies of ten wheat cultivars flour to red flour beetle. Pakistan Journal of Zoology, 18, 257-261.

Mullen, M. A., Vardeman, J. M., \& Bagwell, J. (2012). Insect Resistant Packaging, In D. W. Hagstrum, T. W. Phillips \& G. Cuperus (Eds.), Stored product protection (pp. 135-141). Kansas State University, Manhattan, Kansas.

Mullen, M. A. (1994). Rapid determination of the effectiveness of insect resistant packaging. Journal of Stored Products Research, 30, 95-97. https://doi.org/10.1016/0022-474X(94)90278-X

Mullen, M. A., \& Mowery, S. V. (2000). Insect resistant packaging. International Food Hygiene, 11, $13-14$.

Newton, J. (1988). Insect and packaging -a review. International Bio-Deterioration, 24, 175-187. https://doi.org/ 10.1016/0265-3036(88)90047-4

Odian, G. (2004). Principles of polymerization (4 ed., p. 832). https://doi.org/10.1002/047147875X

Padin, S., Bello, G. D., \& Fabrizio, M. (2002). Grain loss caused by red flour beetle, Sitophilus oryzae and Acanthoscelides obetectus in stored durum wheat and beans treated with Beauveria bassiana. Journal of Stored Product Research, 38, 69-74. https://doi.org/10.1016/S0022-474X(00)00046-1

Qasim, M. U., Hassan, M. W., Wang, J. J., Jamil, M., Iqbal, J., \& Hasan, M. (2013). Management of Tribolium castaneum (Coleoptera: Tenebrionidae) with phosphine fumigation in relation to packaging materials and food types. Pakistan Journal of Zoology, 45, 1639-1645.

Quested, T., Parry, A., Easteal, S., \& Swannell, R. (2011). Food and drink waste from households in the UK. Nutrition Bulletin, 36, 460-467. https://doi.org/10.1111/j.1467-3010.2011.01924.x

Wikström, F., \& Williams, H. (2010). Potential environmental gains from reducing food losses through development of new packaging-A lifecycle model. Packaging Technology and Science, 23, 403-411. https://doi.org/10.1002/pts.906

\section{Copyrights}

Copyright for this article is retained by the author(s), with first publication rights granted to the journal.

This is an open-access article distributed under the terms and conditions of the Creative Commons Attribution license (http://creativecommons.org/licenses/by/4.0/). 